\title{
Highlights of the 2002 Canadian Neurological Society (CNS) Manpower Survey
}

\author{
Peter Bailey, Sharon Warren, Lynda Buske
}

\begin{abstract}
Background: The Canadian Neurological Society commissioned a manpower survey in 2002 to assess demographics, distribution, specialty interests, working conditions, job satisfaction and future plans of neurologists across the country. Methods: A survey was mailed to all known Canadian neurologists $(n=694)$ on two separate occasions. Further encouragement by telephone contact was undertaken. The response rate was 54\%. Results: The mean age of neurologists who responded was 51 years, with $14 \%$ being women. Approximately $55 \%$ of neurologists were community-based. Seventy-six percent designated a sub-specialty interest. On average, neurologists worked 57 hours per week and the majority had significant "on-call" commitments. Job satisfaction was higher among academic neurologists when compared with community-based neurologists, and greater among men than women. A greater percentage of older neurologists were satisfied with their work than their younger colleagues. Significant attrition in the neurological work force is a major concern, since up to $20 \%$ of neurologists reported that they are likely to retire in the next five years and about $15 \%$ are likely to reduce their practice. Conclusions: This survey suggests that substantial concerns are facing Canadian neurology over the next five years. Major efforts to retain existing expertise and enhance residency training will be required to simply maintain the present quality of neurological care in Canada.
\end{abstract}

RÉSUMÉ: Grandes lignes de l'enquête 2002 sur la main-d'œuvre de la Société canadienne de neurologie. Contexte: La Société canadienne de neurologie a commandé une enquête sur la main-d'œuvre en 2002 afin d'évaluer les caractéristiques démographiques, la distribution, les intérêts à l'intérieur de la spécialité, les conditions de travail, la satisfaction au travail et les projets d'avenir des neurologues canadiens. Méthodes: Un questionnaire a été posté à tous les neurologues canadiens $(\mathrm{n}=694)$ à deux reprises. Un rappel téléphonique a été fait. Le taux de réponse a été de $54 \%$. Résultats: L'âge moyen des neurologues qui ont répondu au questionnaire était de 51 ans et $14 \%$ étaient des femmes. À peu près $55 \%$ des neurologues étaient en pratique courante. Soixante-seize pour cent ont mentionné un intérêt pour une sous-spécialité. Les neurologues travaillaient en moyenne 57 heures par semaine et pour la majorité la garde constituait une partie importante de leurs tâches. La satisfaction au travail était plus élevée chez les neurologues du milieu académique que chez les neurologues en pratique courante, et plus élevée chez les hommes que chez les femmes. Un plus grand pourcentage de neurologues plus âgés était satisfait de leur travail que leurs collègues plus jeunes. Une attrition importante au sein de la main-d'œuvre neurologique est une préoccupation majeure considérant qu'environ $20 \%$ des neurologues ont signalé qu'ils prendront probablement leur retraite dans les 5 prochaines années et qu'environ $15 \%$ ont l'intention de réduire leur pratique. Conclusions: Cette étude suggère que la situation de la neurologie canadienne deviendra préoccupante au cours des cinq prochaines années. Il faudra déployer des efforts pour conserver l'expertise existante et rehausser la formation en neurologie pour maintenir la qualité actuelle des soins neurologiques au Canada

Can. J. Neurol. Sci. 2005; 32: 425-432

Canada's neurological history can be traced back to Sir William Osler who wrote extensively about neurological disorders while practicing at McGill University in Montreal from 1873 to 1884 prior to moving to the United States. Several other pioneers in neurology emerged at the turn of the century. These included Goldwin Howland in Toronto and D.A. Shirres at McGill.

During the Second World War a specialized unit known as the "No. 1 Canadian Neurological Hospital" was founded in England that served as a nidus for the development of postwar neurology in Canada. After the Second World War there were approximately 35 neurologists in Canada, many with a primary interest in psychiatry. ${ }^{1}$ By 1975 this number had grown to $240^{2}$ situated mainly in 12 large academic centers. Training of neurologists was in full force by that time with 18 residents graduating each year. By 1986 neurologists numbered 440 (Robert Nelson, unpublished) and by 1994 there were 522 adult neurologists (Alan Guberman, unpublished). There are currently close to 700 neurologists practicing in Canada (2002 Canadian Neurological Society (CNS) manpower survey).

From Dalhousie University (PB), Saint John Campus, Saint John, New Brunswick; Faculty of Rehabilitation Medicine (SW), University of Alberta, Edmonton, Alberta; Canadian Medical Association (LB), Ottawa, Ontario, Canada.

Received February 25, 2005. AcCePted in Final Form June 26, 2005.

Reprint requests to: Peter Bailey, Saint John Regional Hospital, 400 University Ave., Saint John, New Brunswick, E2L 4L2 
In a 60-year-period Canadian neurology has gone from a small cadre of intellectually bright but therapeutically powerless physicians to a large critical frontline medical specialty. Numbers have expanded dramatically from one neurologist per 390,000 persons in 1945 to one neurologist per 44,000 in 2002. In the last two decades, abilities to intervene both diagnostically and therapeutically have exponentially improved and this trend continues. The need for neurological expertise will undoubtedly increase over the forthcoming years.

The survey was undertaken in 2002 by the Canadian Neurological Society to assess current Canadian neurological human resources and provide a background to advocate for the maintenance and improvement of neurological care in the future.

\section{Methods}

A questionnaire was constructed with the advice of the Canadian Medical Association (CMA) and the Rehabilitation Research Centre, University of Alberta, taking into account the survey done in 1994 (Alan Guberman, unpublished). Table 1 lists items included in the questionnaire. Items were primarily closedended, although some open-ended questions were included on issues such as whether the quality of neurological practice was changing. Only an English language version of the questionnaire was produced. Respondents were not asked to put their names on the questionnaire, but they were tracked by their address on the return envelope.

Lists of neurologists were taken from the Southern Medical Directory, the directory of each provincial College of Physicians

\section{Table 1: Items from the 2002 CNS Manpower Survey}

- Type of practice

- Subspecialty

- Method of remuneration

- Number of hours per week spent on specific activities

- Number of new consultations per week and time allotted for new consults

- "On-call" roster, opinion on maximum "on-call", opinion on when "on-call" should no longer be required

- Waiting time for various procedures, percentage of patients who would benefit from various procedures, percentage of neurologists who interpret various tests, percentage who are directors of various labs

- Percentage of neurologists likely to change their practice in next five years

- Satisfaction with career, opinion on whether the quality of practice is changing and whether neurologists would recommend neurology to medical graduates

- Percentage enrolled in the Royal College Maintenance of Certification program, satisfaction with the program and opinion on demands of the program

- Age and gender

- Canadian Neurological Society membership

- Year medical degree obtained and medical school

- Year of certification in neurology, place of residency, certification in another specialty, primarily focused on adult versus paediatric patients

- Province of practice and Surgeons and the CMA Data Bank. Addresses were obtained for 694 neurologists identified as practicing in Canada in the year 2002. All neurologists were mailed an initial survey, including a stamped return envelope addressed to the Canadian Neurological Society office. After a period of two months, a second survey was mailed with the goal of increasing response rate. On a third occasion neurologists were telephoned to encourage them to respond. A total of 371 neurologists responded to the survey, for an overall response rate of 54\%. This resulted in an overall error rate of $+1-5 \%$ at the $95 \%$ confidence level. Response rates varied somewhat by region of the country at: $62 \%(n=59 / 95)$ for British Columbia; 60\% (n=60/100) for Alberta, Saskatchewan and Manitoba combined; 58\% $(\mathrm{n}=137 / 237)$ for Ontario; $37 \%$ $(\mathrm{n}=82 / 222)$ for Quebec; and 77\% $(\mathrm{n}=30 / 39)$ for New Brunswick, Nova Scotia, Prince Edward Island and Newfoundland combined. Based on these response rates, the figures generated for this study should be representative of the neurology population in each province with the possible exception of Quebec.

Data was analyzed using Statistical Package for Social Science (SPSS) for Windows, a PC-based statistical package. Significance level was set at .05 for comparisons between groups based on age, gender, type of practice (academic versus community) and geographic region of Canada. Imbalances in the numbers of some comparison groups (e.g. male/female, geographic region) may have limited power to detect statistically significant differences, so that descriptive statistics were checked for trends.

\section{RESULTS}

The average age of neurologists who responded was 51 years, increased from 48 years in 1996 (CMA survey, unpublished), and $86 \%$ were male. According to the survey, $80 \%$ of neurologists received their basic medical training in Canada. Sixty-five percent received their neurology residency training in central Canada (40\% in Ontario and 25\% in Quebec) compared to $90 \%$ in $1975,{ }^{2}$ confirming that regional training programs are expanding. A comparison between the survey conducted in 1986 (Robert Nelson, unpublished) and the 2002 survey shows that, in a 16-year-period, there was a $46 \%$ increase in the number of neurologists with only a $16 \%$ increase in the Canadian population, thus improving the neurologist to population ratio from 1:60,000 to 1:44,000. There have always been disparities in the distribution of Canadian neurological resources across the country and this is still the case. Most regions of the country have benefited proportionately with the important exception of the Prairie Provinces (Manitoba and Saskatchewan), where in fact the neurologist to population ratio has declined from 1:63,000 in 1986 to the current one of 1:74,000(see Table 2).

The neurologist to population ratio does not necessarily reflect actual clinical capacity. One factor that can intervene is the degree of sub-specialization. As neurology has increased in sophistication and therapeutic options expanded, there has been an increased tendency for sub-specialization and compartmentalization. Seventy-six percent of respondents in the 2002 survey indicated that they focused their practice on one of a number of sub-specialties, as illustrated in Table 3, although not necessarily to the exclusion of other patients.

The percentage of academic compared to community 
Table 2: Neurologist per population by region

\begin{tabular}{c|c|c|c|c|c|c|c}
\hline & Canada & BC & AB & SK/MB & ON & QC & Maritime \\
\hline Neuro/pop & 44.4 & 43 & 43.2 & 74.7 & 50.1 & 33.4 & 61 \\
\hline FTE/pop & 53.9 & 47.5 & 54.2 & 83.3 & 63.6 & 39.4 & 71.79 \\
\hline
\end{tabular}

Neurologist to population ratio is the raw number. Neuro = neurologists, pop = population. Full Time Equivalent (FTE) refers to the reduction in clinical activity based on academic to community ratio in each province, discounting academic neurologists by $32 \%$ for time spent on nonclinical activities

neurologists can also influence clinical capacity. The percentage of neurologists who reported working in an academic setting across the provinces in the 2002 survey were: British Columbia 31\%; Alberta 49\%; Saskatchewan and Manitoba 35\%; Ontario 45\%; Quebec 49\%; New Brunswick, Nova Scotia, Prince Edward Island and Newfoundland 43\%. Academic neurologists spent less time on average in direct patient care than community neurologists (25 versus 40 hours per week respectively).

\section{Work Patterns}

Table 4 provides a breakdown of hours per week spent on specific work activities by Canadian neurologists in the 2002 survey. Neurologists work an average of 56.1 hours per week, with the majority of their time spent on direct patient care. The remainder is spent on research, indirect patient care, administration, teaching, continuing medical education and practice management. As Table 5 shows, $55 \%$ of neurologists utilize feefor-service as their sole source of income. While $44 \%$ have some form of salary input, only $8 \%$ report salary as their sole source of income.

The workweek does not appear to vary between men and women, but trends do occur with age as shown in Table 6 .

Table 3: Percentage of neurologists who identified specific sub-specialty interests*

\begin{tabular}{lc}
\hline Sub-specialty & Percentage \\
Epilepsy & 15 \\
Neuromuscular disorders & 14 \\
Movement disorders & 12 \\
Stroke & 11 \\
Multiple Sclerosis & 11 \\
Pain/headache & 6 \\
Dementia & 5 \\
\hline
\end{tabular}

* A small percentage listed various other sub-specialties
Neurologists in their 40's and 50's have the highest working hours. Older neurologists spend more time on administration and continuing medical education than younger neurologists.

The major clinical activity of a neurologist is consultation. On average community neurologists in the 2002 survey saw 30 new consultations per week, while academic neurologists saw 15. Academics tend to spend more time with each new consultation, the plurality (49\%) taking 60 minutes, while the plurality of community neurologists $(45 \%)$ take 45 minutes, that may be a reflection of case complexity. Neurologists under age 40 and in their 60's spend more time on consultation than those in their 40's and 50's. Women spend longer on new consultations than men: the plurality of women (48\%) spend 60 minutes while the plurality of men $(43 \%)$ spend 45 minutes.

Call is an integral part of a neurologist's work life. Thirtyseven percent of the neurologists in the 2002 survey are "on-call"

Table 4: Practice pattern of all neurologists (average number of hours per week)
Type of Activity

Average hours of direct patient care

Average hours of research

Average hours of indirect patient care

Average hours of administration

Average hours of teaching

Average hours of continuing education

Average hours on Health Care Committees

Average hours of practice management

Other work

Average total hours worked
Average number of hours per week*

31.6

7.3

5

2.5

2.4

3.4

.8

1.5

1.6

56.1
* Average number of hours per week by type of activity. 


\section{Table 5: Methods of remuneration}

\begin{tabular}{c|c|c}
\hline $\begin{array}{c}\text { Method of } \\
\text { Remuneration }\end{array}$ & $\begin{array}{c}\text { Percentage using } \\
\text { this method }\end{array}$ & $\begin{array}{c}\text { Percentage using } \\
\text { this method 100\% } \\
\text { of the time }\end{array}$ \\
\hline Fee for service & $100 \%$ & $55 \%$ \\
Salary & $44 \%$ & $8 \%$ \\
Sessional fees & $13 \%$ & $1 \%$ \\
Capitation & $<1 \%$ & $0 \%$ \\
& & \\
\hline
\end{tabular}

at least one night in five, and $40 \%$ once in 6-15 nights, while $20 \%$ do no call. As would be expected, community neurologists who tend to work in smaller groups have onerous call schedules (45\% at one night in six or less) compared to academics who tend to work in larger centers (29\% at one night in six). On the other hand, more community neurologists $(32 \%)$ than academic neurologists $(13 \%)$ do not do call.

Access to routine neurological care appears to be variable. Fifty-five percent of community neurologists in the 2002 survey and $41 \%$ of academic neurologists could review a routine consultation within eight weeks, suggesting reasonable access for patients. However, $20 \%$ of community neurologists and $24 \%$ of academic neurologists could not accommodate a new referral within three months.
Other services were also limited. Fifty per cent of neurologists reported not having access to routine neurosurgical opinions within ten weeks. Magnetic resonance imaging (MRI) access is also poorly resourced with $70 \%$ of neurologists unable to access a routine MRI scan within ten weeks. Urgent MRI access was considerably better, with $88 \%$ of neurologists able to obtain an urgent scan within seven days, and $37 \%$ within two days.

Neurologists in the 2002 survey also reported limited access to several types of tertiary service, notably: epilepsy surgery, functional neurosurgery, neuropsychological and neuromuscular testing. While all areas seem to be under-serviced, tertiary neuropsychological testing was cited as the largest volume of patients requiring but not receiving services.

Projected neurological sub-specialty needs in local areas over the next five years were assessed and the priority was for cerebral vascular disease sub-specialists, followed by subspecialists in epilepsy and multiple sclerosis.

\section{Career Satisfaction and Quality of Practice}

Seventy percent of neurologists in the 2002 survey reported being satisfied with their career. Only a few (17\%) felt that practice was improving in quality, citing technological advances as the major reason. Alternatively, $46 \%$ felt that practice was deteriorating, citing progressive reduction in resources as the major reason. Nevertheless, $70 \%$ of neurologists would recommend neurology to a medical graduate.

One variable, which appears to determine level of satisfaction, is the decision to enter academic practice. Eightythree percent of academic neurologists in the 2002 survey reported being satisfied with their career, while $69 \%$ of community neurologists said the same. Seventy-six per cent of

Table 6: Average hours per week spent on specific work activities per age category

\begin{tabular}{|c|c|c|c|c|c|}
\hline \multirow{2}{*}{ Type of activity } & \multicolumn{5}{|c|}{ Age categories } \\
\hline & 30's & 40 's & 50's & 60 's & 70's \\
\hline Direct patient care & 31 & 35 & 34 & 29 & 20 \\
\hline Research & 15 & 12 & 12 & 11 & 13 \\
\hline Indirect patient care & 6 & 7 & 5 & 5 & 6 \\
\hline Administration & 3 & 4 & 6 & 7 & 3 \\
\hline Teaching & 3 & 4 & 4 & 4 & 6 \\
\hline CME & 3 & 4 & 4 & 5 & 6 \\
\hline Practice Management & 2 & 3 & 2 & 3 & 3 \\
\hline Committee work & 2 & 2 & 2 & 2 & 2 \\
\hline Total hours & 55 & 61 & 60 & 50 & 36 \\
\hline
\end{tabular}

Indirect patient care is defined as all clinical activities performed which do not directly involve the patient such as filling forms requisitions, reviewing results, arranging other services. $\mathrm{CME}=$ continuing medical education 
academic neurologists would recommend neurology to a medical graduate compared to $64 \%$ of community neurologists.

Fewer female neurologists are satisfied than males. Sixty seven percent of women reported being satisfied with their career compared to $77 \%$ of men. Sixty-two percent of women were willing to recommend neurology to a medical graduate compared to $71 \%$ of men.

Economics obviously play a role in career satisfaction, but the data from the 2002 survey indicate that it is not the only factor. Traditionally British Columbia has had the highest fee schedule in the country, yet only $67 \%$ of British Columbia neurologists report that they are satisfied with their careers compared to $81 \%$ of neurologists in Quebec, which historically has had one of the lowest fee schedules.

Satisfaction with career was also age dependent among neurologists in the 2002 survey. More neurologists over age 60 $(85 \%)$ were satisfied with their career than neurologists in their 40 's (67\%) and 50's (79\%). Older neurologists were more likely to recommend neurology to a medical graduate and to feel that the quality of practice is in fact improving.

Satisfaction with career was also related to region of practice, which in part may be influenced by the ratio of academic to community neurologists. Satisfaction was extremely high in Quebec and Alberta, with more than $80 \%$ of neurologists reporting that they were satisfied. On the other hand, $58 \%$ of neurologists in Saskatchewan and Manitoba reported being satisfied with their career; and $38 \%$ are dissatisfied with their career which is almost four times the national average (38\% vrs $9.9 \%$ ). Possibly as a result, $37 \%$ of neurologists in Saskatchewan and Manitoba are considering retirement within the next five years.

More neurologists in British Columbia reported declines in quality of care than in other regions, with over $70 \%$ feeling that quality of practice was worse than in the past. Higher percentages of neurologists in Alberta and Quebec (both 80\%) would recommend neurology to a medical graduate than in Ontario and British Columbia neurologists (both 60\%).

\section{Provincial Trends}

Health care in Canada is a provincial responsibility and increasingly the administration of health care is occurring at local levels through Regional Health Authorities. Socioeconomic inequalities are clearly reflected in medical human resources and neurology is no exception. The population to neurologist ratio is best in Quebec, followed by British Columbia, Alberta, Ontario, the Atlantic Provinces and the Prairies (see Table 2). Neurologists in the Prairies worked longer hours on average (60 hours per week), saw more patients and had longer waiting lists than neurologists in other regions. They also reported poorer access to support services, such as MRI and neurosurgery.

The percentage of community neurologists in the 2002 survey was lowest in Quebec (50.7\%). British Columbia had the highest percentage of community neurologists (70\%). Age distributions were quite variable. British Columbia had the largest percentage of both older neurologists (25\% over 60 years) and also the largest contingent of young neurologists ( $25 \%$ under 40 years). Ontario had the largest percentage of neurologists over 50 (56\%), while the Atlantic Provinces had the largest percentage under $50(64 \%)$.

\section{Career Plans}

Canadian neurologists who responded to the 2002 survey signaled that significant changes will occur in their career over the next five years. Regardless of type of practice, $20 \%$ of Canadian neurologists who responded reported that they are likely to retire within the next five years and another $15 \%$ are likely to reduce their practice by as much as $50 \%$. Smaller percentages (5 to $7 \%$ ) plan to relocate or change the scope of their practice.

There are some striking regional differences in these figures. Neurologists in the Atlantic Provinces are much more likely to consider moving, up to $20 \%$ willing to consider relocation to another part of Canada or elsewhere. Retirement looms large in the plans of Prairie neurologists (37\%), and British Columbia also has a substantial number $(30 \%)$ of neurologists considering retirement. There is some variation in neurologists who report a desire to reduce their practices by region, but it is slight. Such career changes would obviously have very significant consequences in terms of the delivery of neurological care across Canada.

\section{Physician Resource Evaluation Template}

In conjunction with the Canadian Medical Association, a projection of neurological human resources from the present through to year 2021 was undertaken. This was accomplished using the Physician Resource Evaluation Template (PRET). Physician Resource Evaluation Template is a computermodelling program in which future physician resources can be projected, utilizing historical data to develop scenarios on both the import and export of physicians. ${ }^{3}$ Various scenarios can be projected. The major influx of neurologists is, of course, the number of trainees (at present 24). The major exit is retirement that at the present time is estimated by PRET to be only 12 to 15 neurologists per year.

Two calculations were made using PRET. The first is a crude neurologist to population ratio, and the second a more sophisticated full time equivalency ratio derived by adjusting

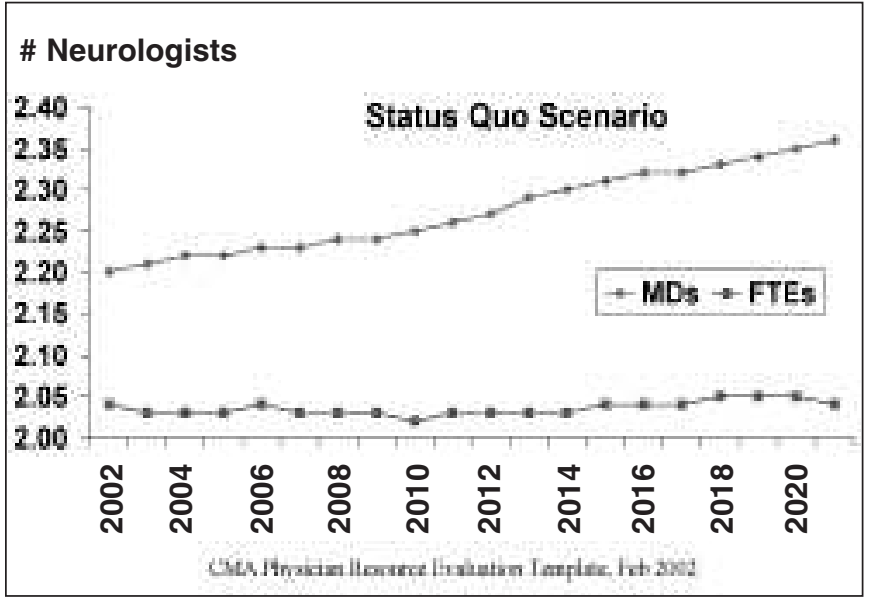

Figure 1: Neurologists and FTEs per 100,000 population in Scenario 1. MDs refers to the crude number of neurologists, Full Time Equivalents (FTE) discounts productivity variables, notably sex and age. 


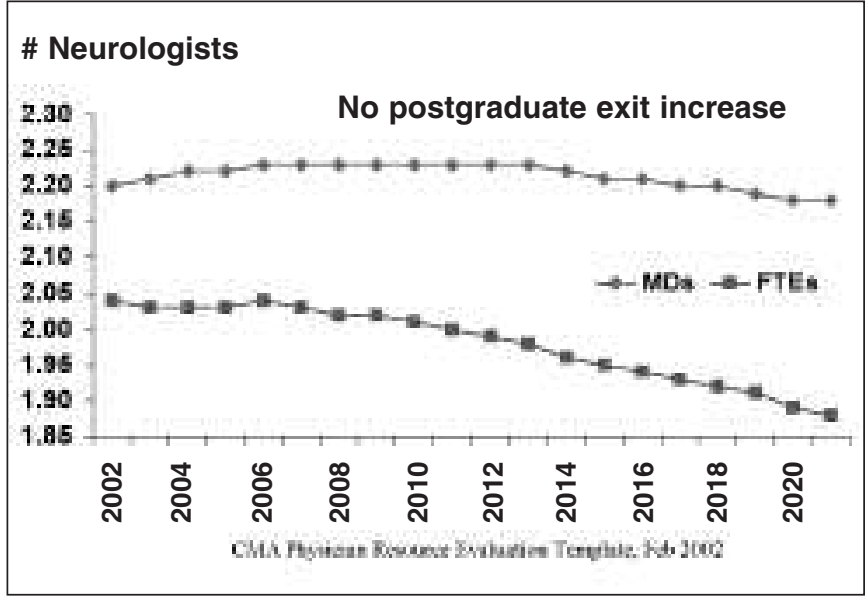

Figure 2: Neurologists and FTEs per 100,000 population in Scenario 2. MDs refers to the crude number of neurologists, Full Time Equivalents (FTE) discounts productivity variables, notably sex and age.

productivity factors such as age and gender. Three scenarios have been generated. The first is a status quo scenario as of 2001 in which the number of neurologists in Canada would progressively increase. This scenario incorporates an increase in Canadian training program output (based on announced increases in undergraduate enrollment) from 24 to 29 residents per-year and assumes that age/gender retirement rates would remain stable (Figure 1). The second scenario would occur if training programs do not rise proportionately relative to overall enrolment increases: a stable crude rate of neurologists to population, but a progressive decline in the full time equivalency ratio as neurologists age and more women enter the field (Figure 2). In the third scenario, if all neurologists retire at age 65 and residency positions remain static, there will be a substantial reduction in neurological manpower (Figure 3).

The 2002 Canadian Neurological Society manpower survey suggests a much more alarming scenario than the PRET, provided there is no response bias. Extrapolating from the plans of those neurologists who responded to the 2002 survey, up to $35 \%$ of practicing neurologists $(244 / 694)$ could retire or reduce their practice. The breakdown of the 2002 respondents suggests that $20 \%$ (140 neurologists) could retire in the next five years (28 per year), which is close to double the number of retirements that were projected based on past behaviour for each age/gender group. This may not be surprising in light of the fact that $20 \%$ of neurologists are over the age of 60 . In addition, the breakdown of respondents suggests that up to 15\% (104 neurologists) could reduce their practice by as much as $50 \%$ leaving a shortfall of 52 neurologists. At the same time, the Canadian population will grow by approximately 1.25 million people requiring an additional 25 neurologists to service that population over the next five years. In addition 5\% will change the scope of practice or emigrate (35 neurologists) These figures suggest that approximately 252 neurologists will be required just to maintain the status quo. Present production of Canadian residents is 24-29 per year, which would indicate a short fall of more than 100 positions over the next five years. This will have a dramatic

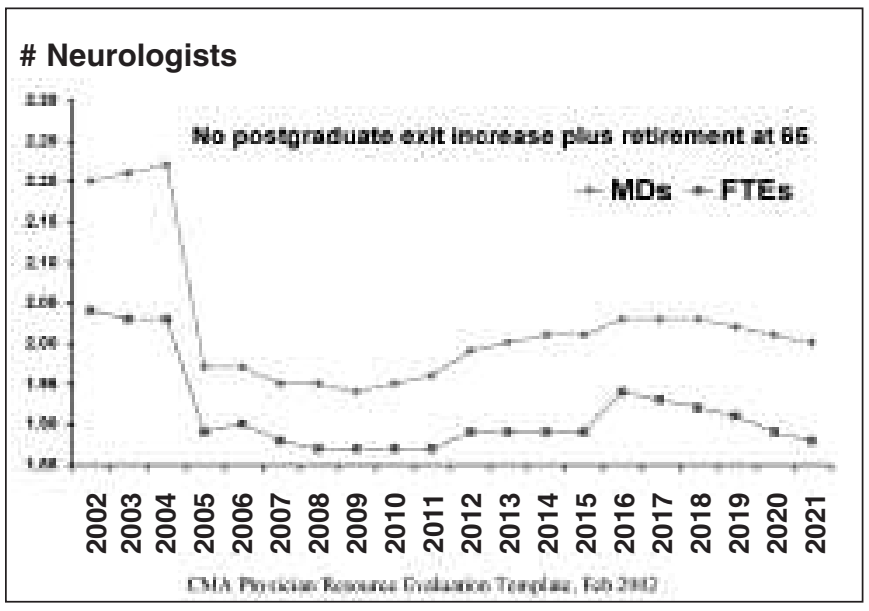

Figure 3: Neurologists and FTEs per 100,000 population in Scenario 3. MDs refers to the crude number of neurologists, Full Time Equivalents (FTE) discounts productivity variables, notably sex and age.

effect on neurological care in the coming years, precisely when the need to expand neurological care is most critical.

\section{Discussion}

The 2002 CNS manpower survey presents a picture of Canadian neurology that is both encouraging and at the same time worrisome.

\section{Implications for Research}

Research in Canadian neurology is steadily growing. There are major international figures in all neurological academic pursuits. The ability of Canadians to bring discoveries from the bench to the bedside has never been stronger. As the survey suggests, the vast majority of neurologists have carved out areas of special interest. Similarly, the vast majority of trainees are now pursuing postgraduate fellowships, similar to American trainees. ${ }^{4}$ The typical Canadian community-based neurologists who are actively involved with research spend on average six hours per week on research. Canadian research consortiums in Stroke, Multiple Sclerosis, Epilepsy, Headache, Tumour Research and Dementia are justifiably perceived as leading the world. There has been important national collaboration in these areas that has brought Canadian neurologists across the country in contact as never before. If these activities are to continue to thrive, there must be adequate human resources and funding.

\section{Implications for Patient Care}

Neurological complaints in Canada account for over $10 \%$ of primary care visits and between 10 to $20 \%$ hospital admissions. ${ }^{5,6}$ In the past 18 years the capability of neurologists to effectively intervene in nearly all neurological conditions has increased exponentially. There has been a tremendous expansion in specialized clinics in the areas of multiple sclerosis, epilepsy, dementia, headache, peripheral nerve disease and stroke. In response to this, neurologists have become more specialized and urbanized, and less interested in performing general community neurology in smaller centres. 
Urgent and emergent neurological care, particularly in these smaller centres, is already under major duress. Many smaller Canadian centres have little or no direct access to a neurologist. For example, recent treatment regimes in stroke demand neurology availability to emergency rooms within 20 minutes, ${ }^{7}$ which is proving problematic. Innovations such as telehealth and teleradiology have been piloted and further broadening of these initiatives will be required. It is clear that many Canadian neurologists have already undertaken a significant burden providing emergency call in groups of five or fewer neurologists. Basic emergency room neurological care will become a major weakness in our health care system if not corrected either by substantially increasing neurological residency training, which appears unlikely, or significantly improving neurological training in internal medicine and emergentology. Currently most internal medicine programs have either no mandatory neurology training or one rotation. A recent French study confirms that a neurologist's opinion in an emergency room is of significant benefit, finding that in $50 \%$ of cases a neurological consultation materially altered the initial clinical diagnosis and management of the patient. ${ }^{8}$

Shortfalls in human resources are also occurring in the area of chronic neurological disease. A recent survey of care for Parkinson's patients in Ontario provides an insight into these unmet needs. Guttman et $\mathrm{al}^{8}$ report that $40 \%$ of Parkinson's patients have not seen a neurologist and only $45 \%$ of patients will see a neurologist annually. With the aging demographics, other chronic degenerative neurological diseases will undoubtedly experience similar gaps in care. Recent work in Alzheimer's dementia foretells of new advances in disease modifying therapies that will require intensive evaluation and time consuming care. ${ }^{9}$ It is unclear whether Canadians will be in a position to take full advantage of these advancements without adequate specialist support.

\section{How many neurologists do we need?}

The estimate of neurological human resource requirements is an extremely complex and difficult calculation. A look around the world illustrates the vast discrepancy in neurological resources. ${ }^{10}$

The largest concentration of neurologists per capita occurs in the former socialist republics with levels as favourable as one neurologist per 6,240 in Lithuania. At the lower end, Pakistan has one neurologist in 4,750,000 persons. In 71 countries there are either no neurologists or the ratio is less than one neurologist per million. In countries with established market economies, an average ratio is one neurologist per 56,100 persons. Most European countries have a figure closer to the American figure of one in 26,100, almost twice that of Canada. Holland, with approximately one neurologist per 25,100 and a socialized wellfunded health care system, might currently provide the best model in which most neurological problems are dealt with by neurologists and hospital care for neurological conditions is under direct neurological supervision. One major factor which allows this model in Holland is a largely urban population concentrated in a small geographical region.

The United Kingdom provides an interesting contrast to Holland, with a meagre workforce of only 380 neurologists for a ratio of one per 177,000 population. General physicians or geriatricians care for nearly all United Kingdom patients in acute settings. Neurologists are basically absent from acute care settings and spend most of their professional lives seeing elective patients. For example, less than $8 \%$ of patients hospitalized with epilepsy see a neurologist. The Association of British Neurologists now advocates tripling their numbers to bring them in line with European standards and begin to provide meaningful care. ${ }^{11}$

An alternative to the PRET for predicting future requirements for physicians is a needs-based model developed in the United States by the Graduate Medical Advisory Committee (GMENAC). This Committee asked a Delphi Panel of experts to reach consensus about needs in various conditions utilizing norms of care and incidence of conditions. ${ }^{12}$ These experts derived the number of hours of neurologist care per 100,000 population for each condition. An example would be migraine, which required the greatest time expenditure: 1,746.9 hours per 100,000 persons. Other conditions which required high time expenditures included non-specific headache, back pain and stroke among 56 other conditions addressed. An estimate was also added for teaching, administration and research. The major issue raised by the GMENAC approach is: what norms of care and what intensity of neurological involvement and monitoring are appropriate? In the 1984 GMENAC exercise to predict needs for 1990, a panel consisting of neurologists suggested a need for 14,520 neurologists while a non-neurologist panel predicted a need for 8,367 neurologists, demonstrating the inherent subjectivity of these types of exercises.

\section{Recommendations}

Based on the results of the 2002 Canadian Neurological Society manpower survey:

1. The Canadian Neurological Society should assess the impact of impending shortfalls in neurological resources on clinical care, research and neurological education in Canada.

2. The Canadian Neurological Society should alert the Canadian public and appropriate authorities to the impending shortfall in neurological services and the detrimental effect this will have on the neurological health of the Canadian population.

3. The Canadian Neurological Society should advocate strongly for the training of more neurologists in Canada.

4. The Canadian Neurological Society should advocate for appropriate training of general practitioners, emergentologists, internists and intensivists, to assure that foreseeable gaps in neurological service are attended to in an expeditious fashion.

5. The Canadian Neurological Society should explore why the quality of neurological practice is perceived to be deteriorating and what steps can be taken to improve working conditions.

6. Alternate methods of neurological care delivery should be further explored utilizing new technology such as telemedicine and other allied health professionals and teams to extend neurological resources.

\section{ACKNOWLeDEMENTS}

The authors thank Linda Aldridge and the staff at the Canadian Congress of Neurological Sciences for superb logistical support and Jan MacMonigle, who phoned many neurologists asking them to comply with the survey. Wonita Janzen and Karen Turpin at the University of Alberta processed 
the data. Dr. Alan Guberman provided helpful advice. The Canadian Neurological Society provided funding for the survey.

\section{REFERENCES}

1. McNaughton R, Feindel W. A Regional History of Neurology in North America: Canada, 496-506.

2. Baxter, D.W. Prospects for Canadian medical neurology. Can J Neurol Sci 1975;2: 101-107.

3. Newton S, Buske L. Physician resource evaluation template: A model for estimating future supply in Canada. Ann RCPSC 1998; 31: 145-150.

4. Stephen M. Sergay, President-elect American Academy of Neurology Personal Communication.

5. Craig J, Paterson V, Rocke L, Jamison J. Accident and emergency neurology: Time for a reappraisal? Health Trends 1997; 29: 8991

6. Moulin T, Berger E, Lemounnaud R, et al. Emergency consultations in the university hospital setting: Contribution of the neurologist to inpatient management. Rev Neurol 2000; 156: 727-735.
7. Proceedings of a National Symposium on Rapid Identification and Treatment of Acute Stroke. National Institute of Neurological Disorders and Stroke, Bethesda, MD, August 1997, NIH Publication No. 97-4329.

8. Guttman M, Slaughter PM, Theriault ME, et al. Parkinsonism in Ontario: Physician utilization. Can J Neurol Sci 2002; 29: 221226.

9. Waldemar G, Dubois B, Emre M, et al. Diagnosis and Management of Alzheimer's disease and other disorders associated with dementia. The role of neurologists in Europe. Eur J Neurol 2000; 7: 133-144.

10. Bergen DC. World Federation of Neurology Taskforce on Neurological Services: Training and distribution of neurologists worldwide. J Neurol Sci 2002; 198: 3-7.

11. Warlow C, Humphrey P, Venables G. UK neurologists and the care of adults with acute neurological problems. Clin Med 2002; 2: 436-439.

12. Garrison LP, Bowman MA, Perrin EB. Estimating physician requirements for neurology: a need-based approach. Neurology 1984; 34: 1218-1227. 